\title{
Urinary Microalbumin Assay
}

National Cancer Institute

\section{Source}

National Cancer Institute. Urinary Microalbumin Assay. NCI Thesaurus. Code C88226.

An immunoassay used for the measurement of microalbumin levels in the urine to determine the glomerular filtration rate. 